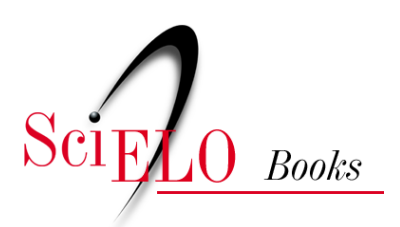

\title{
29. De un primo llamado Óscar
}

\author{
César Augusto Tapias Hernández
}

TAPIAS HERNÁNDEZ, C.A. De un primo llamado Óscar. In: Historias de familia: Etnografía delirante sobre el amor, la violencia y las drogas [online]. Bogotá: Editorial Universidad del Rosario, 2014, pp. 127-130. Textos de ciencias humanas collection. ISBN: 978-958-738-543-4.

https://doi.org/10.7476/9789587385434.0030.

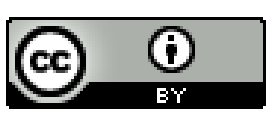

All the contents of this work, except where otherwise noted, is licensed under a Creative Commons Attribution 4.0 International license.

Todo o conteúdo deste trabalho, exceto quando houver ressalva, é publicado sob a licença Creative Commons Atribição 4.0.

Todo el contenido de esta obra, excepto donde se indique lo contrario, está bajo licencia de la licencia Creative Commons Reconocimento 4.0. 


\title{
29. De un primo llamado Óscar
}

\author{
Eso si, el día que nos llegue a faltoniar, que sea lengüilargo, que \\ se alce con una cosa, ese día se muere. \\ Alonso Salazar, No nacimos pa' semilla
}

Cuentan donde Los Monos, unos vecinos de los Tales, que el tío $\mathrm{H}$ era una madre al lado de Óscar, "El Caleño". Que dizque tenía celda propia en la cárcel de tanto entrar y que por aquella época en que estaba de moda aquello de los reboliones, el Óscar decía haber estado en más de uno.

- Por esas mangas donde hoy es el barrio del Doce, como muchas parejas se metían por ahí, dado que eso era tan solo, los pillos los cogían de quieto y lleve... Violaban a las mujeres entre varios — cuenta uno de Los Monos-.

- iSevera moda! — pensaba yo.

¿Sobrino de Gélica o Fonso?... Nadie lo recordaba. Tuve que preguntárselo a mamita. Un día, mientras esperábamos turno para el médico en el Seguro Social de Bello, se lo mencioné y ella dijo que ni de riesgos era familia suya: que ÓsCaR, esa belleza, era familiar de Fonso y que prácticamente era el diablo:

- Con ese sí que había que estar pilas cuando estaba en la casa. Un día nadie supo cómo se le robó un radio a Alberto...

Que le ponían cuidado desde cuando llegaba... pa' dónde se moviera tenía a uno encima, pendiente porque..., ave María, si era ratero. Qué hijuemadre.

- Un día se fue y no se le vio nada, pero cuando nos dimos cuenta fue que se había llevado el radio ese...

Y como que desde esa época donde Los Monos eran hasta de lo más queridos con los extraños...

—Comida no se le niega a nadie, ¡mucho menos un trago! 
En esa casa, dos más arriba de la de mis abuelos, muchos son como Pedro por su casa, y doña Ofelia, como que atendía muy bien al primo Óscar, así como a otros amigos de sus hijos mayores:

—Seguro por eso "El Caleño" nunca nos llegó a fallar — dice Darío, uno de Los Monos.

-Ese lo que era, era un ladrón el hijueputa. El único que lo quería por la casa era don Jorge - cuenta mi papá.

-Ese viejo era quien lo atendía, porque en la casa no lo dejamos volver a entrar - remata mi abuela.

-Él era hijo del hermano mayor de Fonso, y a lo último se fue pa’ Barranquilla y por allá lo mataron... — anota mi papá.

Pero Darío, sobria y hasta medio comprensivamente, comenta:

— "El Caleño" como que tuvo un problema grave en la casa. Mató a la mamá o la madrasta... Algo así.

Y la mamita Gélica me confirma el dato aquel día en el Seguro. En efecto, el hombre había matado a alguien:

-Cuando falleció la mamá, el papá ya tenía otra vieja por ahí lista pa’ casarse y el Óscar se la mató.

La verdad, yo no alcanzo a imaginarme al primo Óscar. A lo mejor tendría la pinta del primo Alberto, otro sobrino de Fonso; pero quizás más bien flaco y con una mirada mucho más asustadora. Aunque no descarto que fuera un pelao hasta pintoso, pues la Miriam, la única mujer en la casa de Los Monos, me confesó que fueron novios dizque por una noche, dice ella, y describió al Óscar como un tipo de unos ojos hermosos, buen cuerpo y una dentadura espectacular:

- Para nada comparable con el primo Alberto.

¿Qué le turbará a uno la mirada? Me pregunto a mí mismo. Además de la bareta, las penas. Solo en el velorio de Ed pude conocer a otros hermanos del papito, pues solo conocía a Virgelina, la mamá del “Gordo” Alberto, y a Francisco, y eso porque cuando él trabajaba en las Empresas Públicas un par de veces pasó por la casa leyendo el contador y mi mamá le sacaba juguito. Así que primos del cucho o tíos como para hacerme a una idea mucho más fiel del Óscar... Nada. Me da la impresión de que todos son medio parecidos de no ser por Francisco, que es moreno...

"El Caleño", un apodo hasta interesante para alguien que de seguro pocos recuerdan, y creo si este álbum llega a servir de algo, será para rememorar personajes, historias y anécdotas quizás ya difuminados en nuestros recuerdos... 
Esta etnografía es una experiencia testimonial que destaca una cultura particular. Se puede notar por las tradiciones y costumbres expresadas cada vez más con el parlache: un uso lingüístico que nos muestra una realidad a través de una simbología manifiesta en la oralidad de las personas entrevistadas... Narradas. Esta es la parte fuerte de lo que usted está terminando de leer: el ejercicio oral como trasfondo de este trabajo que marca el paso a lo largo de la obra, de las reflexiones que no construye del todo el etnógrafo, sino que las compone con lo que dicen los propios etnografiados... Como narrador, he venido proponiendo un juego dialógico que muchas veces resbala en un rasgo repetitivo, un lugar común, cierto anquilosamiento en lo anecdótico que considero, para bien, un nicho etnográfico del que intentan salir a flote rasgos teóricos que se disputan la vocería del autor, que no pretendo ser. Así parece que me pierdo en la repetidera de algunos asuntos, como la cita constante al uso drogas.

No pretendo explicar a fondo lo que propone este significante en el entretejido que es mi familia como práctica, como forma de ser y su conexión con la violencia, de eso hay mucho en Fumando mañas (Tapias, 2010). Aquí solo quiero ver que funciona como una verdad común, como una base de nuestra estructura simbólica, inconsciente forma de vida, material de escritura, ingrediente para una etnografía delirante sobre una familia disfuncional, como casi todas en nuestra sociedad... Y aunque parezca necesario revisar con cuidado este problema para dotar de sentido los diálogos y las situaciones que se presentan al lector, me pregunto hasta dónde importa el sentido. ¿Cómo tienen que ser los estudios de los fenómenos humanos y sociales para que resulten valiosos en sí mismos y sirvan, además, de orientación a los reformadores sociales? Responderá la crítica que esos estudios deben ser objetivos. Y ¿cómo lograr esa objetividad?

Las condiciones básicas para la conquista de la objetividad, según Linton (1965), son un punto de vista impersonal y un espíritu amplio. Soy amplio de mente y de espíritu, pero esto que trascribo no puede dejar de ser personal, autobiográfico, autoetnográfico... No soy objetivo, pero voy libre entre palabras que no pronuncio yo... Solo las recolecto. Y en el cómo las recolectó, en el método que empleo... Ahí está lo social científico:

Lamentablemente, existen prácticas muy extendidas entre los pretendidos científicos que, so copa de noble amor a la verdad, cubren deficiencias intelectuales y - ¿por qué no decirlo? - prescripciones éticas, como la búsqueda de pruebas 
con el mero objeto de echar por tierra una teoría en boga, la racionalización para justificar un determinado plan, o restar importancia a hechos que no se ajustan a las propias ideas preconcebidas. (Martín López, 1993, p. 65)

"Ninguna ciencia que se ocupa de los seres humanos podrá alcanzar nunca el grado de objetividad de que son susceptibles las ciencias físicas y las biológicas. Nadie podrá estudiar a una persona con la misma impasibilidad con que estudiaría a una rata blanca o un fósil, pues se encontrará demasiado ligado al objeto de su estudio" (Linton, 1965, p. 12). El delirio de las drogas, en cuanto objeto que me sujeta a los demás, es un factor emotivo cuya influencia es cada vez más directa, pues el objeto es un fenómeno de la cultura.

Por eso esta etnografía escamotea varios problemas sin solucionarlos. Bosqueja una serie de factores emotivos que discurren... siendo historias... y ¿qué más puedo decir sobre esos factores, sobre esas historias?, por ejemplo, sobre mi padre que no deja de beber... Sobre mí que no dejo de drogarme... El problema, dice Reynoso, no es tanto ser o no objetivo, sino cómo lograr la objetividad. En un estudio como este ¿cómo podría ser objetivo si miro a mi propia gente? Además, lo hago tan embriagado como ellos... El camino no es propiamente la embriaguez, sino la escritura... ¿Escribir como borracho? ¿Estar tan borracho como el borracho? ¿Ser otro borracho?

Para salir de este embrollo, podemos ver a Piaget (1964), quien apoyado en los planteamientos marxistas propone que se reoriente la relación entre el sujeto cognoscente $(\mathrm{S})$ y el objeto de conocimiento $(\mathrm{O})$ para concebirla de forma dialéctica. Ello implica la existencia de una interacción mutua y en movimiento entre los dos elementos de la relación, como lo diría el filósofo chino Zhuang Zi, también llamado Chuang Tzu: de modo que mutuamente, opuestos, este y oeste (yo y el otro), somos incapaces de negarnos mutuamente... La dialéctica, como un interesante esfuerzo de síntesis... una salida que Ricoeur (1990) termina por aclarar cuando plantea entender que la objetividad no solo está ligada a la subjetividad que posee el científico social que reconstruye la historia o la cultura, sino, además, a la subjetividad del otro, entendiendo al "otro" en el sentido más amplio de la palabra. 